\title{
Failure envelopes of pile groups under inclined and eccentric load
}

\author{
M. IOVINO*, R. M. S. MAIORANO†, L. DE SANCTIS
}

\begin{abstract}
A novel numerical procedure for defining failure envelopes of pile groups under inclined and eccentric load is proposed. The starting point is a closed-form exact solution for interaction diagram of pile groups under combined axial-moment loading recently published in the literature. Failure envelopes in the generalised force space are then derived as an extension of this solution by means of an incremental algorithm. It is shown that the axial load at foundation level has always a beneficial effect on the lateral capacity of the pile group, even if this favourable effect is often neglected in practice. On the contrary, the amount of interaction between the horizontal and moment components of the resultant action at failure is usually very small, with the exception of piles groups with end-bearing piles. Some example applications of the proposed method are provided and a simple, yet reliable procedure for ultimate limit-state analysis of pile groups subjected to inclined and eccentric loads is suggested.
\end{abstract}

KEYWORDS: bearing capacity; limit state design/analysis; piles \& piling

Published with permission by the ICE under the CC-BY 4.0 license. (http://creativecommons.org/licenses/by/4.0/)

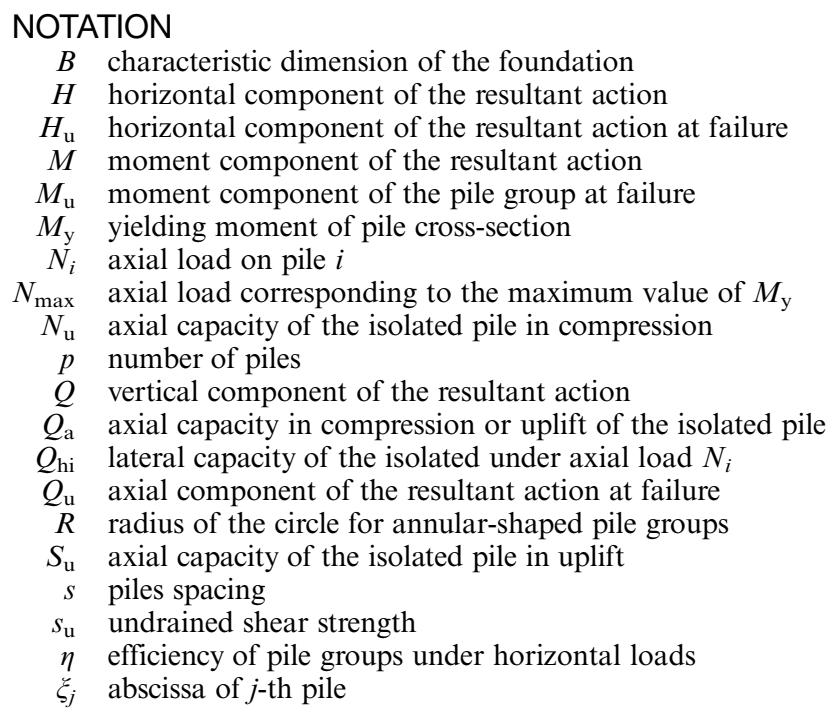

\section{INTRODUCTION}

The most widespread design approach in geotechnical engineering for pile groups under eccentric and inclined loads is based on independent calculation of the safety level against vertical and horizontal modes of failure. On the contrary, the large demand of tall, slender structures usually subjected to large, multi-component loads has led to design methodologies based on the concept of 'failure envelope' where the 'coupling' effect among the components of the

Manuscript received 26 May 2021; accepted 20 July 2021.

Published online at www.geotechniqueletters.com on 6 October 2021.

*Department of Engineering, University of Napoli Parthenope, Napoli, Italy (Orcid:0000-0001-7755-9054).

$\dagger$ Department of Engineering, University of Napoli Parthenope, Napoli, Italy (Orcid:0000-0001-7452-9001).

Department of Engineering, University of Napoli Parthenope, Napoli, Italy (Orcid:0000-0002-0547-4171).

\$Department of Engineering, University of Napoli Parthenope, Napoli, Italy (Orcid:0000-0002-0263-757X). resultant action is explicitly taken into account. This concept has been applied extensively over the last decades to many foundation types, including shallow foundations (Nova \& Montrasio, 1991; Butterfield \& Gottardi, 1994; Taiebat \& Carter, 2000; Gourvenec \& Randolph, 2003; Gourvenec, 2007; Vulpe et al., 2014), skirted and caisson foundations (Bransby \& Randolph, 1998; Gourvenec \& Barnett, 2011) and spudcan foundations (Martin \& Houlsby, 2001; Cassidy et al., 2004). The advantage of this approach over classical superposition (Brinch Hansen, 1970) is manifold as widely discussed in Nova \& Montrasio (1991) and Gottardi \& Butterfield (1993). Failure envelopes can be used to assess the capacity and proximity to failure surface of a foundation under combined loading or employed as ingredients for plasticity-based macro-element models. Their application to engineering foundation problems is also recommended by ISO (2016).

The problem of the failure locus of a pile group in the generalised force space $(Q, H, M / B)$, with $Q, H$ and $M$ being the vertical, lateral and moment components of the resultant action and $B$ the characteristic dimension of the foundation, has been traditionally investigated on an experimental basis. Such works include small-scale tests on groups of aluminium piles embedded in both sand (Kishida \& Meyerhof, 1965; Meyerhof \& Ranjan, 1973; Meyerhof et al., 1983) and saturated clay (Saffery \& Tate, 1961; Meyerhof, 1981; Meyerhof \& Yalcin, 1984). As an outcome of these tests, semi-empirical interaction relationships in both the $(Q, M)$ and $(Q, H)$ planes are available (Meyerhof \& Ranjan, 1972; Meyerhof et al., 1983; Meyerhof \& Yalcin, 1984). The combination of eccentric and inclined loads is handled in terms of a reduction factor of the vertical capacity under purely axial load, rather than through a generalised equation in the force space. Semi-empirical, approximate expressions of this factor are available in both sand (Meyerhof et al., 1983) and clay (Meyerhof \& Yalcin, 1984). However, the yielding moments of the aluminium piles are so high that the collapse mechanism under lateral load does not follow the long pile mode (Broms, 1964a, 1964b), which is instead the most common mode of failure. Hence, their applicability in practice is at least questionable. 
A novel exact solution for failure envelopes of pile groups in the general case of unevenly distributed, dissimilar piles under combined axial-moment loading has been determined by Di Laora et al. (2019) throughout an application of the theorems of limit analysis. The basic hypotheses of this approach are: $(a)$ piles idealised as uniaxial rigid-perfectly plastic elements; $(b)$ piles' connecting cap idealised as a rigid body; $(c)$ connections of the piles to the cap modelled as hinges. The only ingredients needed for this calculation are the axial capacity in compression, $N_{\mathrm{u}}$, and in uplift, $-S_{\mathrm{u}}$, of the piles belonging to the group. As an extension of this study, the focus is set herein on the failure envelopes of pile groups within planes parallel to $(Q, H)$ and $(H, M)$. Since the horizontal capacity of each pile depends on the properties of its cross-sectional area and the amount of applied axial load, which in turn must lie in between $\left(-S_{\mathrm{u}}\right.$, $N_{\mathrm{u}}$ ). Some example applications of this approach are provided. Finally, a simple criterion for ultimate limitstate analysis of pile groups under generalised loads is suggested.

\section{MATHEMATICAL FRAMEWORK}

The procedure for determining the failure envelopes in planes parallel to $(Q, H)$ or $(H, M)$ has been developed for the general case of unevenly distributed, dissimilar piles. However, for the convenience of the reader, the conceptual flow which the mathematical framework is based on is herein described with regard to the case of unevenly distributed, identical piles. The starting point is the interaction diagram in the $(Q, M)$ plane. In this respect, reference is made to the exact solution by Di Laora et al. (2019), a polygon with $2 p$ vertexes in the $(Q, M)$ plane, whose coordinates are:

$$
\begin{gathered}
\left\{\begin{array}{c}
Q_{\mathrm{ui}}=(i-1) N_{\mathrm{u}}-(p-i+1) S_{\mathrm{u}} \\
M_{\mathrm{ui}}=-N_{\mathrm{u}} \sum_{j=1}^{i-1} \xi_{j}+S_{\mathrm{u}} \sum_{j=i}^{p} \xi_{j}
\end{array} \quad i=1, \ldots, p\right. \\
\left\{\begin{array}{c}
Q_{\mathrm{uk}}=-(k-1) S_{\mathrm{u}}+(p-k+1) N_{\mathrm{u}} \\
M_{\mathrm{uk}}=S_{\mathrm{u}} \sum_{j=1}^{k-1} \xi_{j}-N_{\mathrm{u}} \sum_{j=k}^{p} \xi_{j}
\end{array} \quad k=1, \ldots, p\right.
\end{gathered}
$$

where $p$ is the number of piles, $Q_{\mathrm{u}}$ and $M_{\mathrm{u}}$ are the ultimate axial load and moment of the pile group and $\xi_{j}$ is the abscissa of $j$-th pile along with the direction perpendicular to the resultant moment vector. Figure 1 shows the interaction diagram of a row of four equally spaced, identical piles with $S_{\mathrm{u}} / N_{\mathrm{u}}=3 / 4$, as an example. As already discussed by Di Laora et al. (2019), the vertexes of this polygon

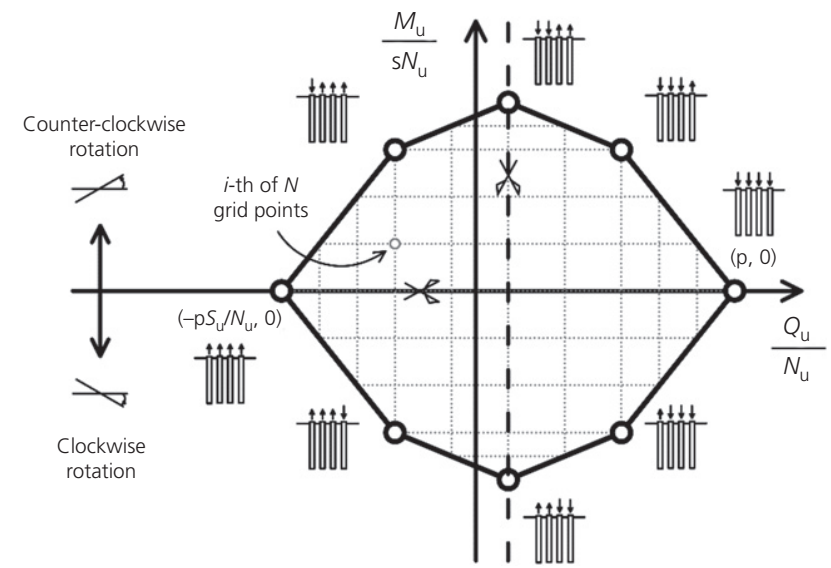

Fig. 1. Interaction diagram in the $(Q, M)$ plane for a row of four identical, equally spaced piles correspond to failure modes where the cap displaces by rotation about a point in between two adjacent piles, while the conjunction lines represent failure modes where the cap displaces by rotation about the head of a pile. According to this last failure mode, all piles achieve their axial capacity in compression or uplift, with the exception of the pile corresponding to the centre of rotation. The problem of the failure envelopes within planes parallel to $(Q, H)$ and $(H, M)$ is solved numerically, through an incremental procedure which accounts for the relationship between the axial load atop the pile, $N$, and the yielding moment of its cross-sectional area, $M_{\mathrm{y}}$. To this aim, the interval $\left(-p S_{\mathrm{u}}, p N_{\mathrm{u}}\right)$ is first partitioned so as to identify a grid of $(Q, M)$ points, as shown in Fig. 1. An incremental algorithm is then used to calculate the axial load distributions on piles corresponding to the grid points, according to the following steps:

(1) The axial load distribution is first supposed to be linear so as to satisfy only equilibrium conditions:

$$
N_{\mathrm{i}}=\frac{Q}{p}+\frac{M}{\sum_{i=1}^{n} \xi_{i}^{2}} \xi_{i} \quad i=1, \ldots, p
$$

(2) The following ratios are then calculated for all the piles:

$$
q_{\mathrm{i}}=\frac{N_{\mathrm{i}}-Q_{\mathrm{a}}}{Q_{\mathrm{a}}}
$$

where $Q_{\mathrm{a}}$ is the axial capacity of the $i$-th pile in compression or uplift - that is, $Q_{\mathrm{a}}=N_{\mathrm{u}}\left[-S_{\mathrm{u}}\right]$ if $N_{\mathrm{i}}<0[>0]$. Negative

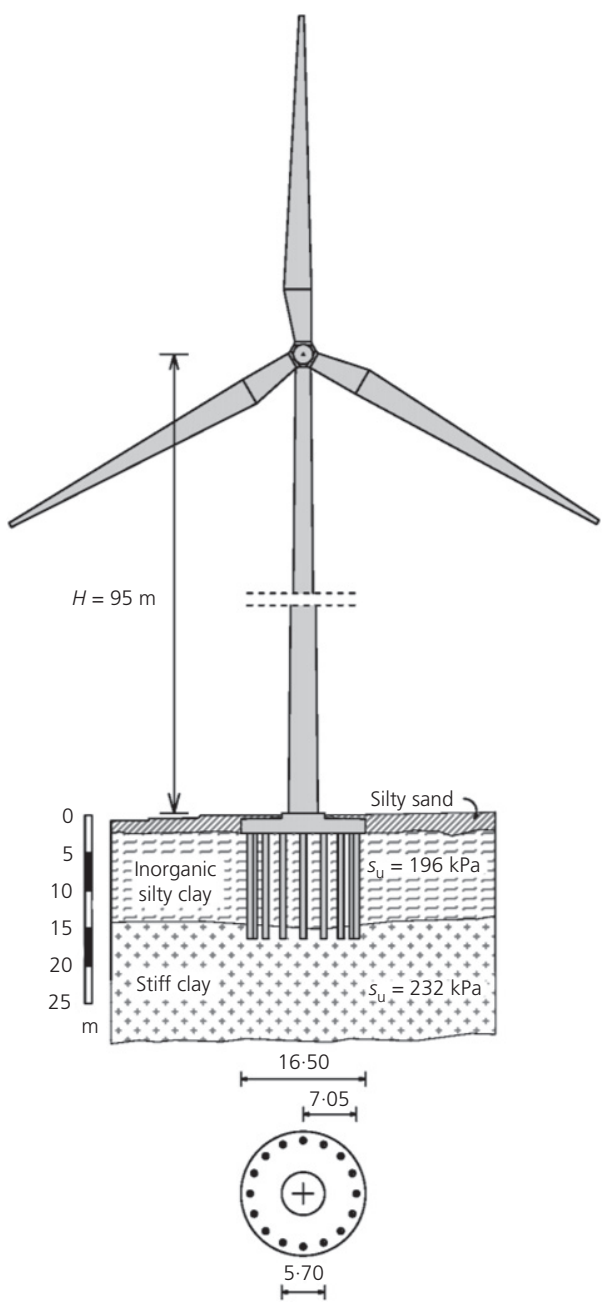

Fig. 2. Plan view and cross-section of a wind turbine foundation in southern Italy 
values of the above ratio indicate that piles have not achieved their axial capacity. In this case the linear assumption does not violate the failure criterion and the procedure terminates. By contrast, the occurrence of positive values of $q$ suggest that one or more piles have attained failure. In this case, the axial load acting on the pile with the highest $q$ is set equal to $N_{\mathrm{u}}$ or $-S_{\mathrm{u}}$, depending on the sign of $N_{\mathrm{i}}$, and the proportion of the external moment corresponding to the mobilisation of $Q_{\text {a }}\left(M_{1}\right)$ is calculated.

(3) The residual value of the external moment, $M-M_{1}$, is applied on the pile group obtained by subtracting the yielded pile from the original layout, and the axial load distribution on piles is thus updated by summing the linear distribution corresponding to $\left(Q, M_{1}\right)$ to that coming from the residual moment.

(4) Once again, the axial load distribution should not violate the failure criterion defined for the piles. Should this not be the case, the previous steps are repeated until the residual moment is zero.

Once the $N_{\mathrm{i}}$ values have been determined, the yielding moments $M_{\mathrm{yi}}$ at piles' heads are computed from the equation of the $\left(N, M_{\mathrm{y}}\right)$ interaction diagram of the cross-sectional area of the pile. The lateral capacity of the $i$-th pile, $Q_{\mathrm{hi}}$, is then calculated according to the well-known theory by Broms (1964a, 1964b). The lateral capacity of the pile group for any $(Q, M)$ pair of the grid is finally evaluated as

$$
H_{\mathrm{u}}=\eta \sum_{1}^{n} Q_{\mathrm{h} i}
$$

where $\eta$ is the efficiency of the pile group. For long and intermediate failure modes, the contribution of the yielding moments $M_{\mathrm{yi}}$ to the lateral capacity of the group is therefore explicitly taken into account. Notably, the piles' connections to the cap are modelled as rigid-plastic fixities in this case.

Another noteworthy point is that inclined loads on piles evaluated with the proposed procedure do not violate the failure criterion of the isolated pile in the $(Q, H)$ plane. Hence, in the realm of the limit analysis theorems, the lateral capacity of the group calculated from equation (5) is a lower-bound solution. The above procedure has been implemented in a Matlab code. Some example applications are provided in the following.

\section{APPLICATION TO CASE STUDIES \\ A wind farm in Southern Italy}

The case study of a wind farm in Southern Italy is first examined. Each wind turbine is founded on a circular raft enhanced with 16 cast-in situ bored piles $22 \mathrm{~m}$ long and $0.8 \mathrm{~m}$ in diameter embedded in over-consolidated clay and arranged along with a circumference with radius $R=7 \cdot 05 \mathrm{~m}$, as shown in Fig. 2. This case study was already examined by Di Laora et al. (2019) to highlight the advantages of the theoretical solution for failure envelops in $(Q, M)$ plane based on limit analysis theorems. As discussed by the authors, the application of this innovative approach would have allowed to reduce the pile length from 22 to $14 \mathrm{~m}$. This
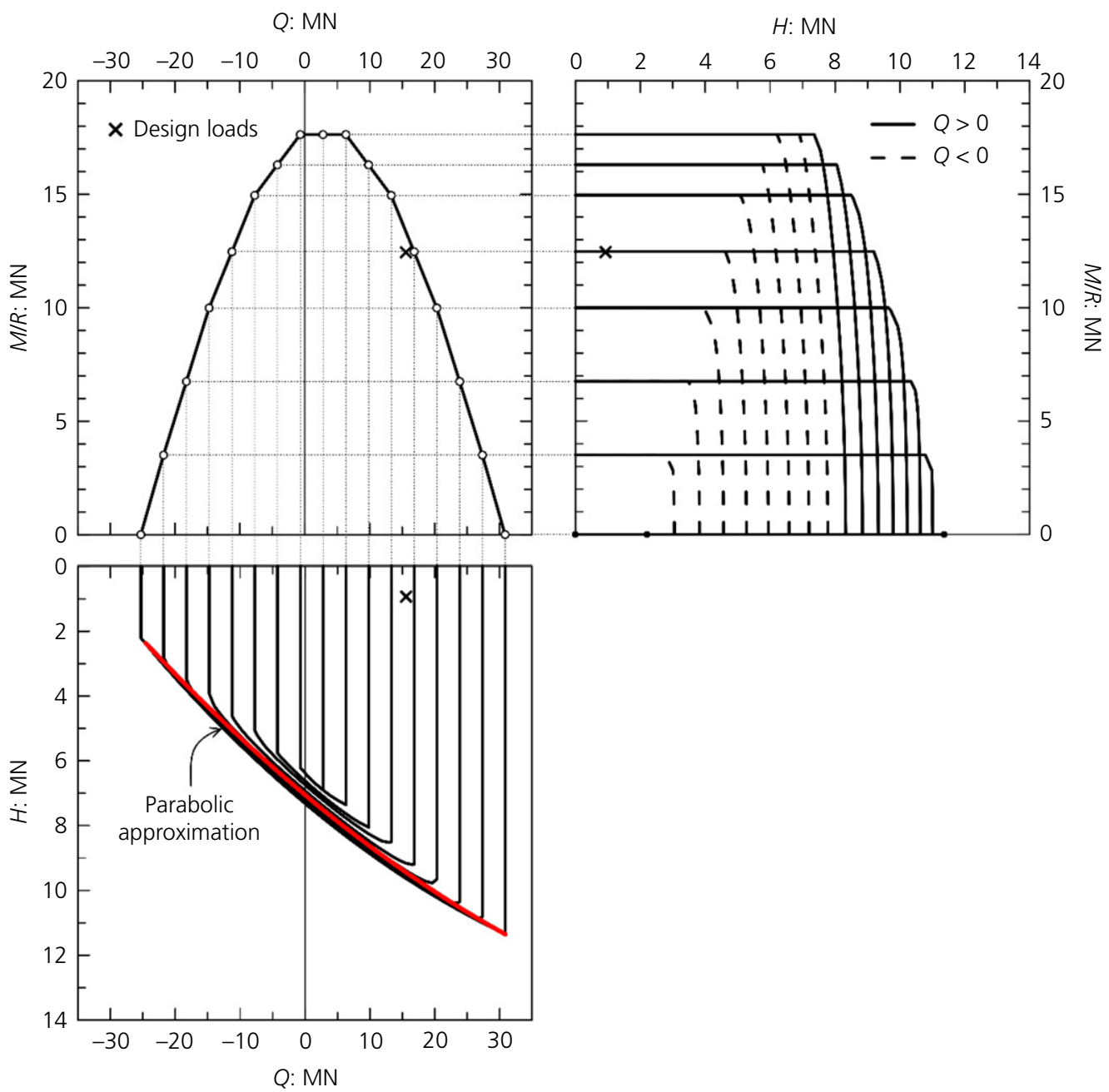

Fig. 3. Interaction diagrams in case of floating piles 
last layout (case $a$ ) is considered for the purpose of this study. Figure 3 illustrates the failure envelopes of the pile group in the $(Q, M / R)$ plane evaluated through equations (1) and (2) and in planes parallel to $(Q, H)$ and $(Q, M / R)$ determined

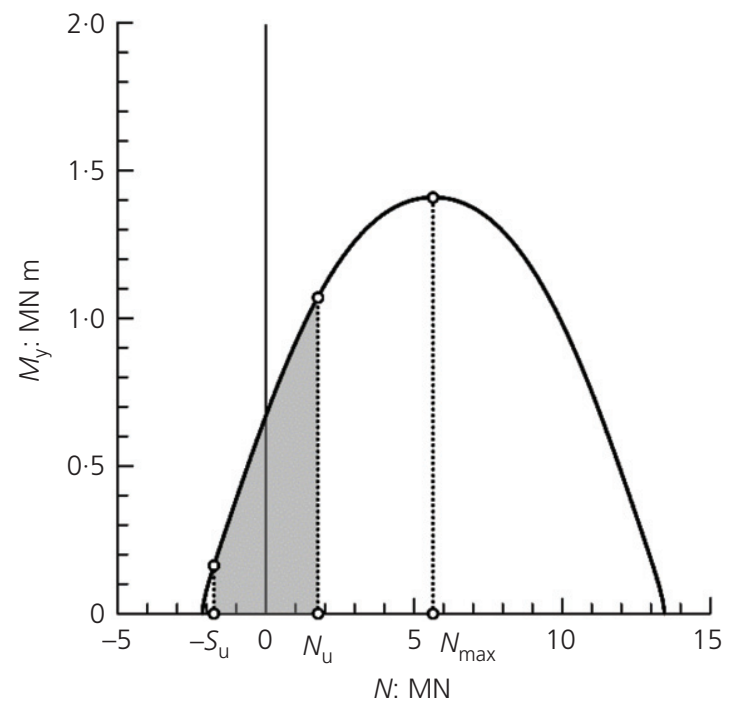

Fig. 4. $N-M_{y}$ interaction diagram of circular reinforced-concrete cross-section in case of floating piles through the proposed procedure. Yielding moments within piles were evaluated from the axial load distribution on piles using the simplified expression of Di Laora et al. (2020), in which the longitudinal rebar arrangement is idealised with a thin steel ring having an equivalent area of $32 \mathrm{~cm}^{2}$ and a radius of $33 \mathrm{~cm}$. The relevant amount of interaction between the ultimate vertical and horizontal components is due to the intense relationship between the axial load and the yielding moment of the cross-sectional area of the pile (Fig. 4). The failure surfaces in the $(Q, H)$ plane for different values of $M$ fall within a very narrow band, suggesting that the lateral capacity is mainly affected by the amount of axial load. The same conclusion can be easily drawn from the failure envelopes in the $(H, M / R)$ plane. The components of the resultant action under extreme wind conditions are also plotted in Fig. 3 for comparison.

The picture may be different in case of end-bearing piles. To shed light on this situation, the stiff layer in Fig. 2 is replaced by a soft rock (case $b$ ), so as to ideally increase the unit resistance at the pile base. In this case, 12 piles with a diameter of $0.6 \mathrm{~m}$, a length of $14 \mathrm{~m}$ and a longitudinal rebar with equivalent area of $32 \mathrm{~cm}^{2}$ and a radius of $23 \mathrm{~cm}$ are sufficient to withstand the moment loading induced by extreme wind conditions. The interaction diagrams of this foundation are illustrated in Fig. 5. Contrarily to case $(a)$, the failure envelopes in the $(Q, H)$ plane are no longer confined in a narrow band as the influence of the moment component on the lateral capacity of the foundation under the dead load of the tower is not negligible. This is due to the fact that the
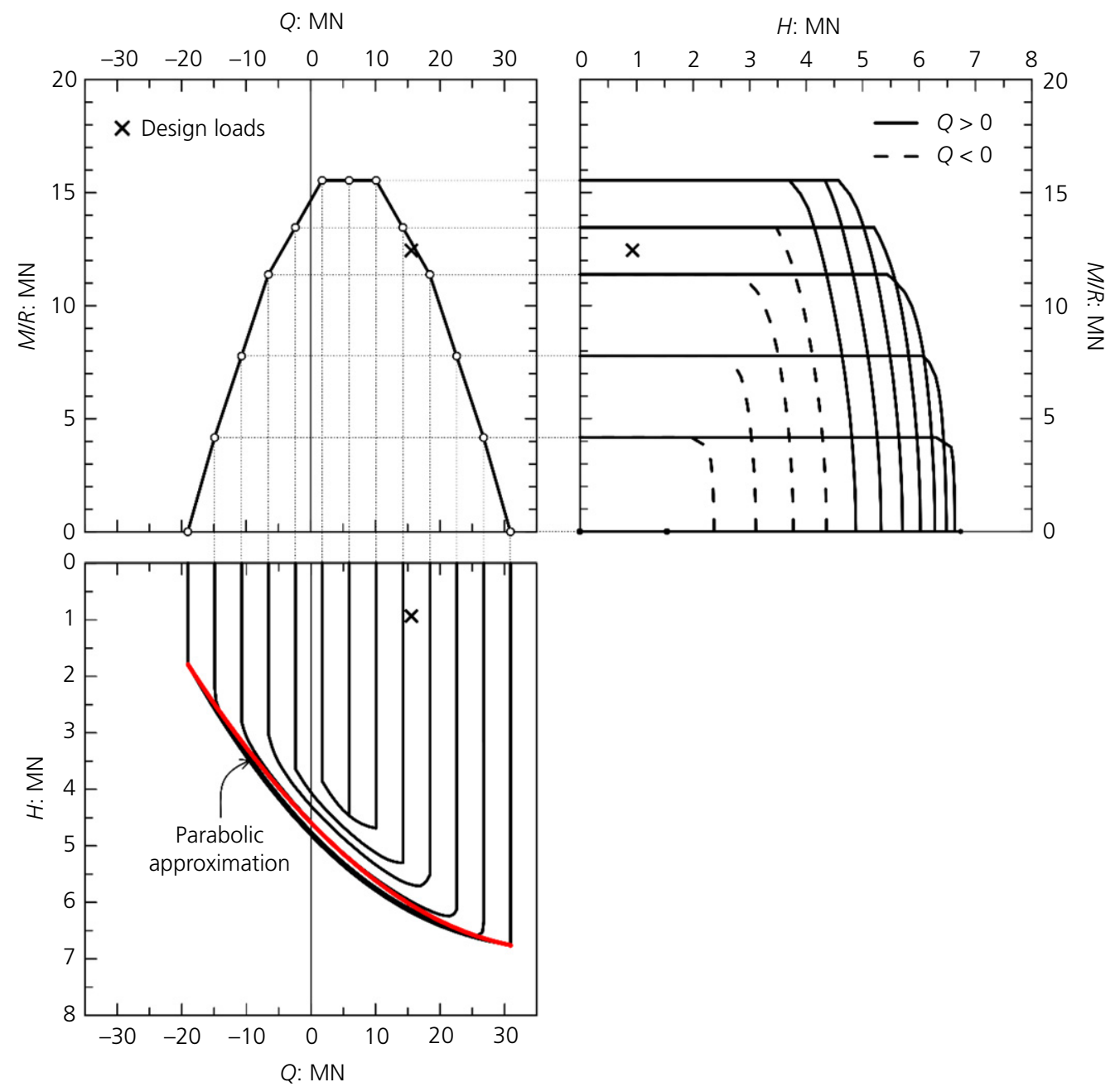
$\left(N, M_{\mathrm{y}}\right)$ relationship in the wider reference interval $\left(-S_{\mathrm{u}}, N_{\mathrm{u}}\right)$ is markedly non-linear (see Fig. 6).

\section{Small-scale models for centrifuge testing}

The attention is placed on a subset of model foundations recently tested in the $10 \mathrm{~m}$ diameter Turner Beam Centrifuge of the University of Cambridge by de Sanctis et al. (2021) with the aim of validating experimentally the theoretical

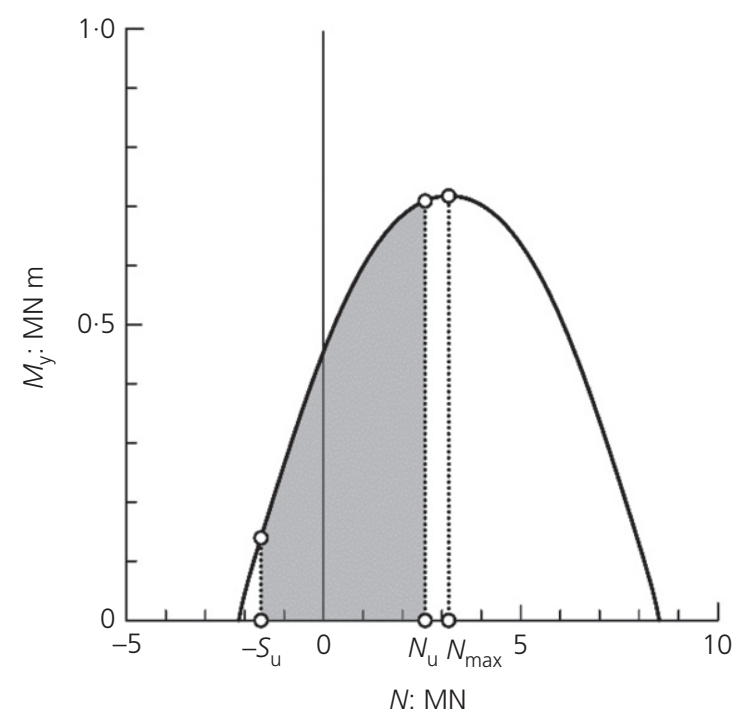

Fig. 6. $N-M_{y}$ interaction diagram of circular reinforced-concrete cross-section in case of end-bearing piles solution by Di Laora et al. (2019). Centrifuge tests were carried out at $50 \mathrm{~g}$ on annular-shaped pile groups $(R=3 \mathrm{~m})$ consisting of eight aluminium piles hinged at the top and isolated piles embedded in a kaolin clay layer (Fig. 7). The model piles were $50 \mathrm{~mm}$ thick close-ended hollow cylinders, with an outer diameter of $500 \mathrm{~mm}$ and an embedded length of $12 \mathrm{~m}$ (at prototype scale). Also shown in Fig. 7 is the undrained shear strength, $s_{\mathrm{u}}$, profile obtained from a cone penetration test (CPT) carried out with a miniature CPT device after the swing down stage. For the purpose of this example application, the curve labelled CPT in Fig. 7 can be replaced by a constant profile with $s_{\mathrm{u}}=13.7 \mathrm{kPa}$. Loading tests on two isolated piles allowed to evaluate the axial capacities and, hence, the interaction diagram in the $(Q, M / R)$ plane. The failure envelopes in planes parallel to $(Q, H)$ and $(H, M / R)$ calculated with the procedure proposed herein are illustrated in Fig. 8. Yielding moments $M_{\mathrm{yi}}$ are calculated from axial loads using the closed-form solution of Rotter \& Sadowski (2017) for tubes with small thickness. Notably, piles are free-to-rotate and fail according to the short mode (Broms, 1964a) - that is, without the occurrence of plastic hinges. In this situation, the lateral capacity of piles belonging to the group is unaffected from the yielding moments and, hence, from the distribution of axial loads on piles. As a consequence, there is no 'interaction' at failure between the horizontal load and the other two components of the resultant action on the foundation.

\section{IMPLICATIONS IN DESIGN}

Figure 9 illustrates the failure envelope for a pile group (case $a$ ) in the generalised force space. As an alternative to

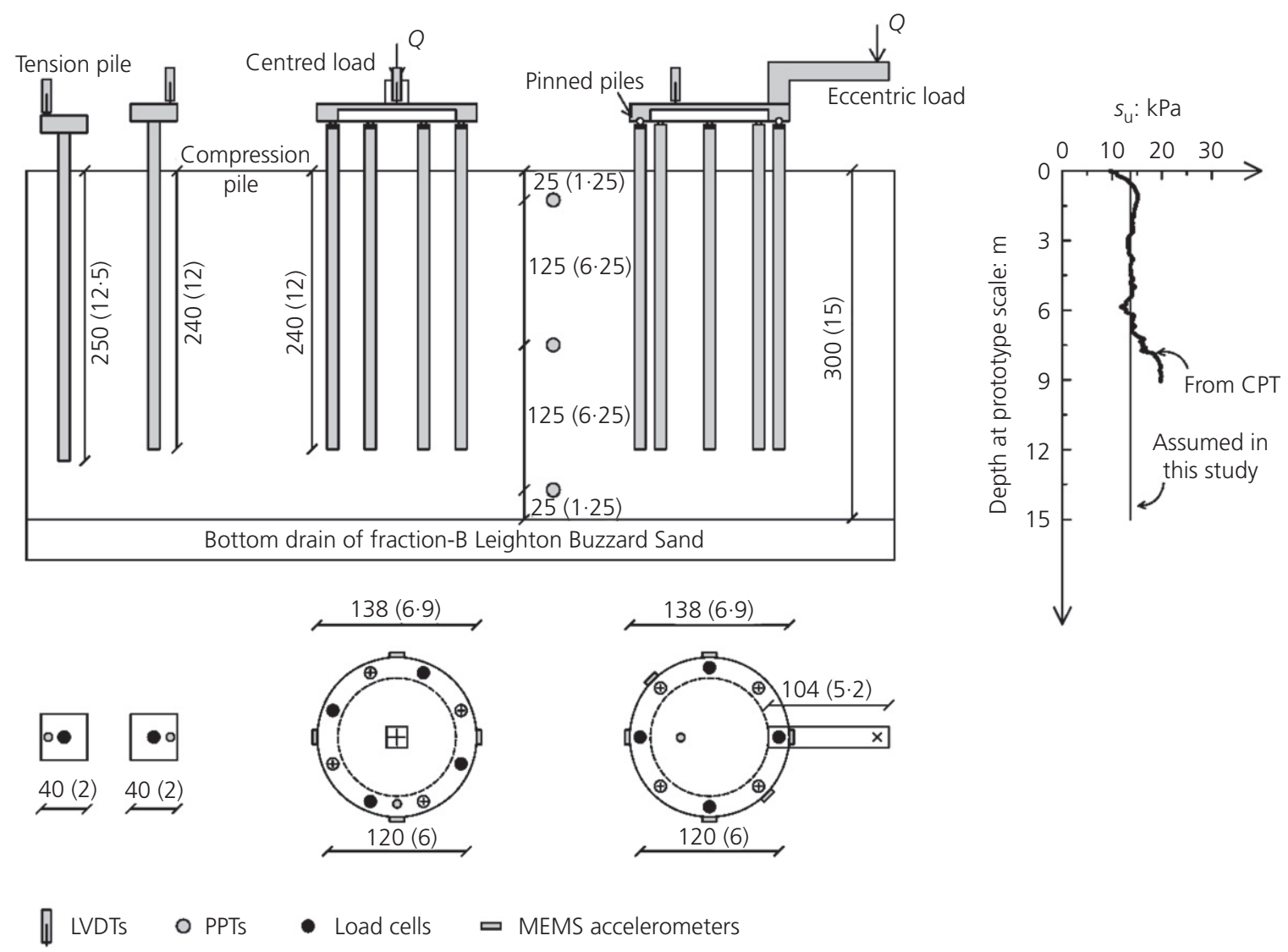

Fig. 7. Model pile foundations tested in centrifuge. Model (prototype) dimensions are in $\mathrm{mm}(\mathrm{m})$. LVDTs, linear variable differential transformer; PPTs, pore pressure transducers; MEMS, microelectromechanical systems (source: modified after de Sanctis et al. (2021)) 


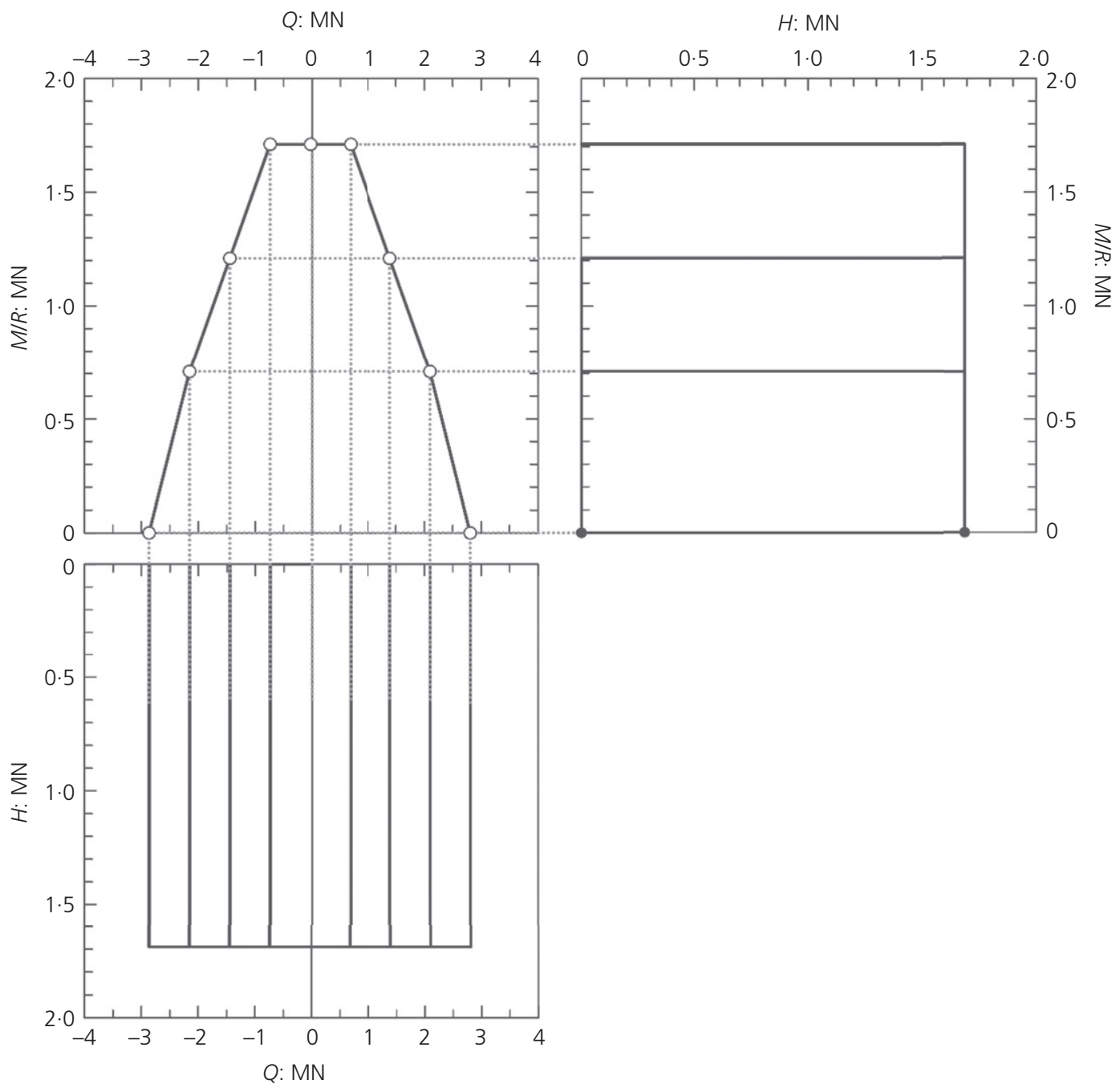

Fig. 8. Interaction diagrams for pile group tested in the centrifuge

the construction of this spatial domain, the following simplified procedure can be adopted. The failure envelopes in the $(Q, M)$ and $(Q, H)$ planes are first evaluated. The interaction diagram for $M=0$ can be conveniently approximated through the unique parabolic equation:

$$
\begin{aligned}
& H_{\mathrm{u}}=a Q_{\mathrm{u}}^{2}+b Q_{\mathrm{u}}+c \\
& a=\frac{Q_{\mathrm{h} 1}-Q_{\mathrm{h} 2}}{n\left[S_{\mathrm{u}}^{2}-N_{\mathrm{u}}^{2}+2 N_{\max }\left(S_{\mathrm{u}}+N_{\mathrm{u}}\right)\right]} \\
& b=-2 a n N_{\max } \\
& c=n \frac{Q_{\mathrm{h} 2} S_{\mathrm{u}}^{2}-Q_{\mathrm{h} 1} N_{\mathrm{u}}^{2}+2 N_{\max }\left(Q_{\mathrm{h} 2} S_{\mathrm{u}}+Q_{\mathrm{h} 1} N_{\mathrm{u}}\right)}{S_{\mathrm{u}}^{2}-N_{\mathrm{u}}^{2}+2 N_{\max }\left(S_{\mathrm{u}}+N_{\mathrm{u}}\right)}
\end{aligned}
$$

where $\left(Q_{\mathrm{h} 1}, Q_{\mathrm{h} 2}\right)$ are the lateral capacities of the isolated pile evaluated at $\left(-S_{\mathrm{u}}, N_{\mathrm{u}}\right)$, while $N_{\max }$ is the axial load corresponding to the maximum value of $M_{\mathrm{y}}$. As shown in Figs 3 and 5, equation (6) matches satisfactorily the interaction diagram determined by the numerical approach for both floating and end-bearing piles.

The above envelopes can be conveniently represented into a unique tripartite plot with the axial load variable on the $x$-axis. In many practical situations, the foundation can be considered safe enough against failure when the points of coordinates $(Q, H)$ and $(Q, M)$ fall inside their respective interaction diagrams. Of course, care must be taken in case of end-bearing piles when the $(Q, H)$ pair falls in proximity

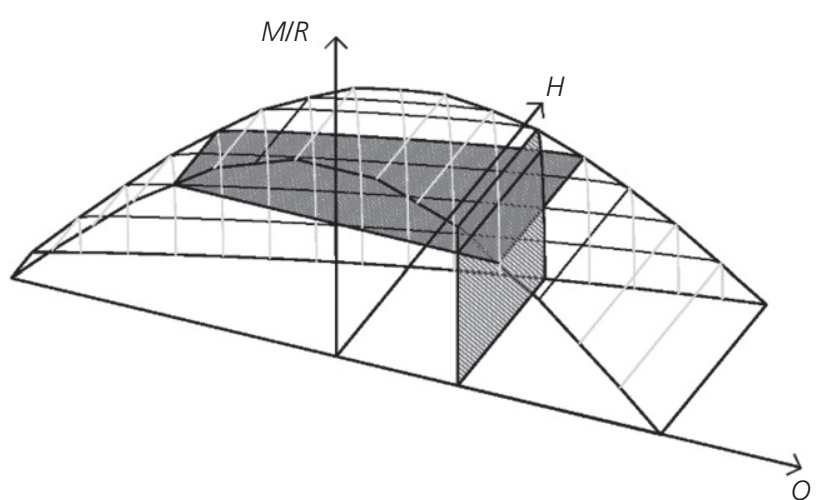

Fig. 9. Failure envelope in the generalised force space

of the parabolic envelope, provided that the amount of interaction between the lateral load and moment capacity might not be negligible in this case.

\section{CONCLUSIONS}

A simple approach for determining the failure locus of pile groups in the generalised force space is presented and discussed. The starting point is a recent exact solution for failure envelopes under combined axial-moment loading 
based on theorems of limit analysis. As an extension of this study, failure envelopes in the space of loads are calculated through an incremental procedure in which the dependence of the lateral capacity of the foundation from the yielding moments of the cross-sectional area of piles is explicitly taken into account.

Some example applications are provided as the basis for a discussion about the mechanisms of interaction at failure between the components of the resultant action. It is shown that the axial load at foundation level, as that due to the dead load of the structure, always has a beneficial effect on the lateral capacity of the foundation. On the contrary, the amount of interaction at failure between the horizontal and moment components is usually very small. Groups of end-bearing piles might be an exception to this last conclusion.

A simple approach based on hand calculation of two analytical domains in a tripartite plot is also proposed for practical estimation of the safety conditions of a pile group subjected to inclined and eccentric load.

\section{ACKNOWLEDGEMENTS}

This work has been carried out under research project MIUR PRIN 2017 'A new macro-element model for pile groups under monotonic, cyclic and transient loads' granted by the Italian Ministry for Research and University.

\section{REFERENCES}

Bransby, M. F. \& Randolph, M. F. (1998). Combined loading of skirted foundations. Géotechnique 48, No. 5, 637-655, https://doi.org/10.1680/geot.1998.48.5.637.

Brinch Hansen, J. (1970). A revised and extended formula for bearing capacity. Bulletin No. 2, Danish Geotechnical Institute, Copenhagen, Denmark.

Broms, B. B. (1964a). Lateral resistance of piles in cohesive soils. J. Soil Mech. Found. Div. 90, No. SM2, 27-63.

Broms, B. B. (1964b). Lateral resistance of piles in cohesionless soils. J. Soil Mech. Found. Div. 90, No. SM3, 123-156.

Butterfield, R. \& Gottardi, G. (1994). A complete threedimensional failure envelope for shallow footings on sand. Géotechnique 44, No. 1, 181-184, https://doi.org/10.1680/geot. 1994.44.1.181.

Cassidy, M. J., Byrne, B. W. \& Randolph, M. F. (2004). A comparison of the combined load behaviour of spudcan and caisson foundations on soft normally consolidated clay. Géotechnique 54, No. 2, 91-106, https://doi.org/10.1680/geot. 2004.54.2.91.

de Sanctis, L., Di Laora, R., Garala, T. K., Madabhushi, S. P. G., Viggiani, G. M. B. \& Fargnoli, P. (2021). Centrifuge modelling of the behaviour of pile groups under vertical eccentric load. Soils Found. 61, No. 2, 465-479.

Di Laora, R., de Sanctis, L. \& Aversa, S. (2019). Bearing capacity of pile groups under vertical eccentric load. Acta Geotech. 14, No. 1, 193-205.

Di Laora, R., Galasso, C., Mylonakis, G. \& Cosenza, E. (2020). A simple method for $N-M$ interaction diagrams of circular reinforced concrete cross sections. Struct. Concr. 21, No. 1, 48-55.

Gottardi, G. \& Butterfield, R. (1993). On the bearing capacity of surface footings on sand under general planar loads. Soils Found. 33, No. 3, 68-79.

Gourvenec, S. (2007). Failure envelopes for offshore shallow foundations under general loading. Géotechnique 57, No. 9, 715-728, https://doi.org/10.1680/geot.2007.57.9.715.

Gourvenec, S. \& Barnett, S. (2011). Undrained failure envelope for skirted foundations under general loading. Géotechnique $\mathbf{6 1}$, No. 3, 263-270, https://doi.org/10.1680/geot.9.T.027.

Gourvenec, S. \& Randolph, M. (2003). Effect of strength non-homogeneity on the shape of failure envelopes for combined loading of strip and circular foundations on clay. Géotechnique 53, No. 6, 575-586, https://doi.org/10.1680/geot. 2003.53.6.575.

ISO (2016). 19901-4: Petroleum and natural gas industries - specific requirements for offshore structures - part 4: geotechnical and foundation design considerations. Geneva, Switzerland: ISO.

Kishida, H. \& Meyerhof, G. G. (1965). Bearing capacity of pile groups under eccentric loads in sand. Proceedings of the 6th international conference on soil mechanics and foundation engineering, Montreal, Canada, vol. 2, pp. 270-274. Toronto, ON, Canada: University of Toronto Press.

Martin, C. M. \& Houlsby, G. T. (2001). Combined loading of spudcan foundations on clay: numerical modelling. Géotechnique 51, No. 8, 687-699, https://doi.org/10.1680/geot. 2001.51.8.687.

Meyerhof, G. G. (1981). The bearing capacity of rigid piles and pile groups under inclined loads in clay. Can. Geotech. J. 18, No. 2 , 297-300.

Meyerhof, G. G. \& Ranjan, G. (1972). The bearing capacity of rigid piles under inclined loads in sand. I: vertical piles. Can. Geotech. J. 9, No. 4, 430-446.

Meyerhof, G. G. \& Ranjan, G. (1973). The bearing capacity of rigid piles under inclined loads in sand. III: pile groups. Can. Geotech. J. 10, No. 3, 428-438.

Meyerhof, G. G. \& Yalcin, A. S. (1984). Pile capacity for eccentric inclined load in clay. Can. Geotech. J. 21, No. 3, 389-396.

Meyerhof, G. G., Yalcin, A. S. \& Mathur, S. K. (1983). Ultimate pile capacity for eccentric inclined load. J. Geotech. Engng 109, No. 3, 408-423.

Nova, R. \& Montrasio, L. (1991). Settlements of shallow foundations on sand. Géotechnique 41, No. 2, 243-256, https://doi.org/10.1680/geot.1991.41.2.243.

Rotter, J. M. \& Sadowski, A. J. (2017). Full plastic resistance of tubes under bending and axial force: exact treatment and approximations. Structures 10, 30-38.

Saffery, M. R. \& Tate, A. P. K. (1961). Model tests on pile groups in clay soil with particular reference to the behaviour of the group when it is loaded eccentrically. Proceedings of the 5th international conference soil mechanics and foundation engineering, Paris, France, vol. 5, pp. 129-134. Paris, France: Dunod.

Taiebat, H. A. \& Carter, J. P. (2000). Numerical studies of the bearing capacity of shallow foundations on cohesive soil subjected to combined loading. Géotechnique 50, No. 4, 409-418, https://doi.org/10.1680/geot.2000.50.4.409.

Vulpe, C., Gourvenec, S. \& Power, M. (2014). A generalised failure envelope for undrained capacity of circular shallow foundations under general loading. Géotech. Lett. 4, No. 3, 187-196. 